\title{
АНАЛИЗ РАЗМЕЩЕНИЯ ПРОСТРАНСТВЕННЫХ СТРУКТУР ПО СУБЪЕКТАМ РФ 1
}

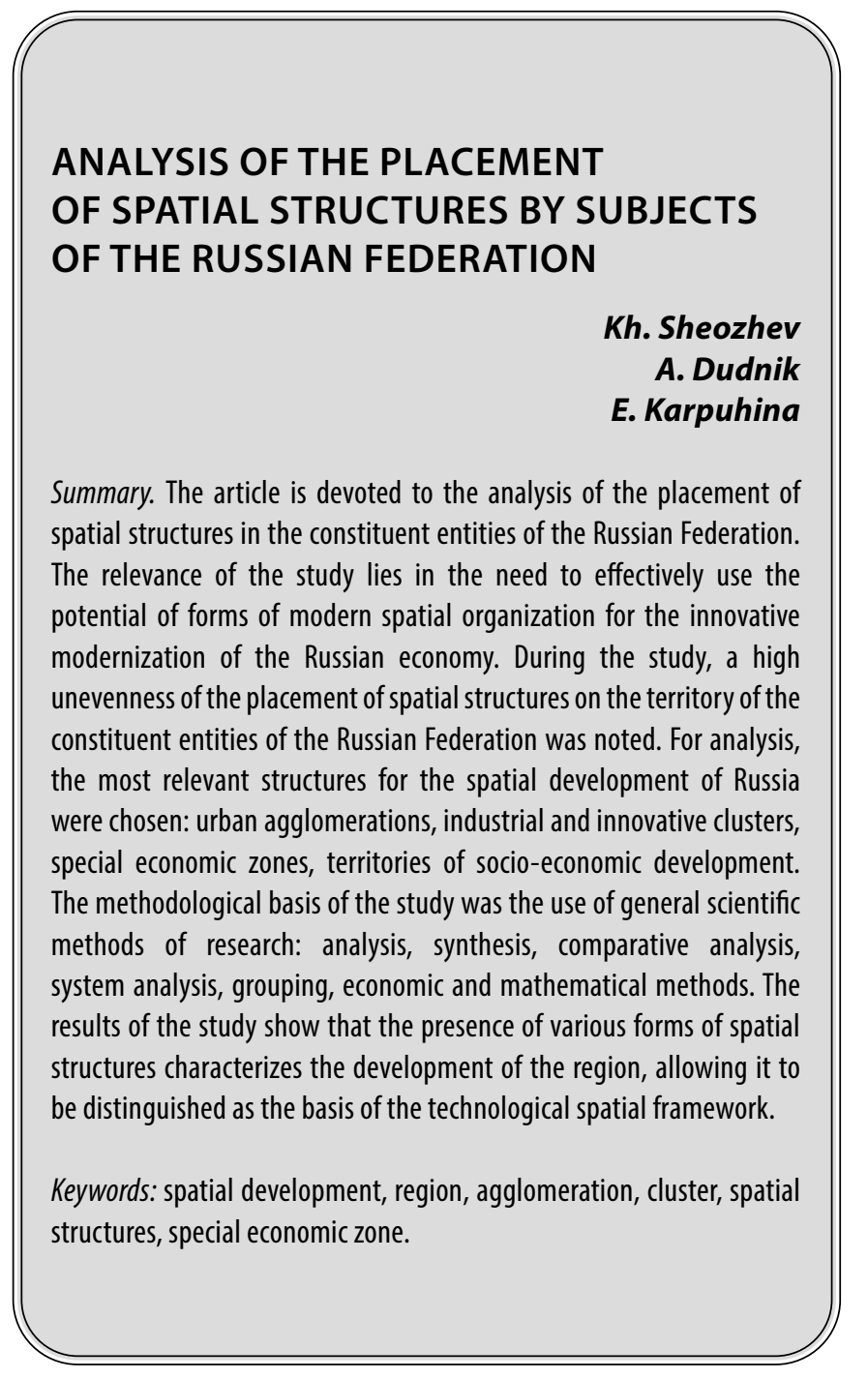

$\Pi$ овышение конкурентоспособности российской экономики после завершения этапа восстановления - одна из ключевых задач современной России. Для инновационная модернизация российской экономики широко используется потенциал форм ее пространственной организации (агломерации, кластеры, ТОСЭР, ОЭЗ, свободные порты (СПВ) и др.) с учетом современных факторов размещения производительных сил.

\author{
Шеожев Хасанби Владимирович \\ Д.э.н., профессор, Финансовый университет при \\ Правительстве РФ \\ KVSheozhev@fa.ru \\ Дудник Анна Игоревна \\ М.н.с., Финансовый университет при \\ Правительстве РФ \\ Annetdd@gmail.com \\ Карпухина Елена Евгеньевна \\ Лаборант-исследователь, Финансовый \\ университет при Правительстве РФ \\ EEKarpukhina@fa.ru
}

Аннотация. Статья посвящена анализу размещения пространственных структур по субъектам РФ. Актуальность исследования заключается в необходимости эффективного использования потенциала форм современной пространственной организации для инновационной модернизации российской экономики. В ходе проведения исследования, была отмечена высокая неравномерность размещения пространственных структур на территории субъектов РФ. Для анализа были выбраны наиболее актуальные структуры для пространственного развития России: городские агломерации, промышленные и инновационные кластеры, особые экономические зоны, территории социально-экономического развития. Методической основой исследования стало применение общенаучных методов исследования: анализ, синтез, сравнительный анализ, системный анализ, группировка, экономико-математические методы. Результаты проведенного исследования свидетельствуют о том, что наличие разнообразных форм пространственных структур характеризует развитость региона, позволяя выделить его в качестве основы технологического пространственного каркаса.

Ключевые слова: пространственное развитие, регион, агломерация, кластер, пространственные структуры, особая экономическая зона.

Представленные инструменты государственной политики выступают в качестве долгосрочной тенденции пространственного развития Российской Федерации. Размещение пространственных структур на территории субъектов РФ отличается неравномерностью. Для анализа были выбраны наиболее актуальные структуры для пространственного развития России: городские агломерации, промышленные и инновационные кластеры, особые экономические зоны, территории

' Статья подготовлена по результатам исследований, выполненных за счет бюджетных средств по государственному заданию Финуниверситету. 


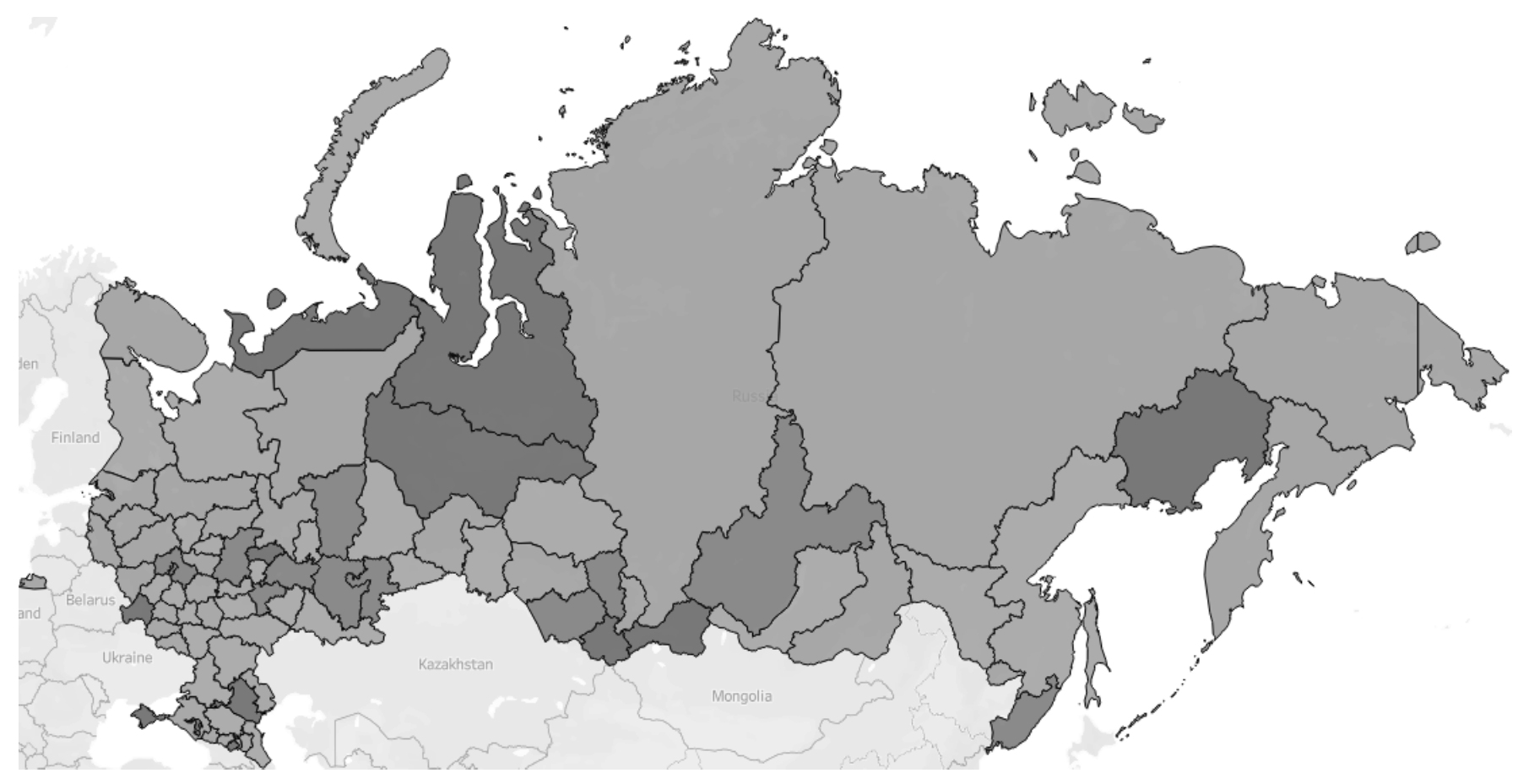

Рис. 1. Распределение пространственных структур по субъектам РФ Источник: выполнено авторами по материалам [1, 2, 3, 4].

социально-экономического развития. Анализ их территориальной концентрация по регионам позволяют представить их визуальное распределение на карте следующим образом (рисунок 1):

Красным цветом обозначены регионы, в которых отсутствуют любые виды пространственных структур. Оранжевым цветом выделены субъекты РФ, в которых имеется 1-2 пространственные структуры. Светло-зеленый цвет на карте использован для регионов с общим количеством пространственных структур не превышающих 3-5 единиц. Темно-зеленым цветом отмечены регионы, в которых располагаются 6-17 пространственных структур различного типа. В РФ наиболее высоким уровнем пространственной концентрации характеризуется: Республика Татарстан (17ед.), Челябинская область (12ед.), Алтайский край - 9ед.

Лидерами по количеству агломераций (2ед.) среди субъектов РФ стали Республика Татарстан и Ставропольский край. Стратегия Пространственного развития Российской Федерации на период до 2025 годы выделяет 20 городских агломераций, обеспечивающие более $1 \%$ экономического роста страны и 21 городскую агломерация, обеспечивающие 0,2-1\% экономического роста. Центр стратегических разработок выделяет следующие наиболее конкурентоспособные потенциальные агломерации: Санкт-Петербург, Москва, Екатеринбург, Челябинск, Пермь, Нижний Новгород, Казань,
Самара. К ключевым особенностям агломераций можно отнести высокую концентрацию ресурсов, что приводит к более высоким экономическим результатам агломераций по сравнению с остальной территорией страны, тем самым выделяя агломерацию в качестве драйвера развития своей страны [5].

Одним из самым часто используемых инструментов стала кластеризация. Помимо очевидных лидеров (г. Москва (бед.), г. Санкт-Петербург (4ед.) абсолютными лидерами по количеству территориальных кластеров стали Республика Татарстан (8ед.), Челябинская область (7ед.), Алтайский край (5ед.). Промышленные кластеры преобладают в Москве, индустриальные кластеры - в Пермском крае. Только на территории 75 субъектов РФ размещена кластерная структура. К ключевым особенностям кластеризации можно отнести: максимальную эффективность за счет эффекта масштабов, выгодность в силу узкой специализации, увеличение возможности кластера за счет расширения границ кластерных связей.

К началу 2020 года на территории РФ были созданы 30 Особых Экономических Зон, в том числе три из них на территории приоритетных геостратегических субъектов РФ - в Калининградской, Магаданских областях, в Республике Крым и городе федерального значения Севастополе. Наиболее значительно число ОЭЗ среди субъектов РФ отмечено в Московской области (Зед.), 
Таблица 1. Потенциальные регионы опорного каркаса пространственного развития России по размещению пространственных структур

\begin{tabular}{|c|c|}
\hline Макрорегион & Регионы \\
\hline Центральный & $\begin{array}{l}\text { г. Москва } \\
\text { Московская обл. }\end{array}$ \\
\hline Центрально-Черноземный & $\begin{array}{l}\text { Воронежская обл. } \\
\text { Липецкая обл. }\end{array}$ \\
\hline Северо-Западный & $\begin{array}{l}\text { г. Санкт-Петербург } \\
\text { Республика Карелия }\end{array}$ \\
\hline Северный & Архангельская обл. \\
\hline Южный & \begin{tabular}{|l} 
Ростовская обл. \\
Волгоградская обл.
\end{tabular} \\
\hline Северо-Кавказский & $\begin{array}{l}\text { Республика Дагестан } \\
\text { Ставропольский край }\end{array}$ \\
\hline Волго-Камский & $\begin{array}{l}\text { Республика Татарстан } \\
\text { Пермский край } \\
\text { Нижегородская обл. }\end{array}$ \\
\hline Волго-Уральский & $\begin{array}{l}\text { Республика Башкортостан } \\
\text { Ульяновская обл. }\end{array}$ \\
\hline Уральско-Сибирский & $\begin{array}{l}\text { Челябинская обл. } \\
\text { Свердловская обл. }\end{array}$ \\
\hline Южно-Сибирский & $\begin{array}{l}\text { Алтайский край } \\
\text { Кемеровская обл. }\end{array}$ \\
\hline Ангаро-Енисейский & $\begin{array}{l}\text { Иркутская обл. } \\
\text { Красноярский край }\end{array}$ \\
\hline Дальневосточный & $\begin{array}{l}\text { Приморский край } \\
\text { Республика Бурятия } \\
\text { Хабаровский край } \\
\end{array}$ \\
\hline
\end{tabular}

Источник: выполнено авторами

Москве (2ед.), Республике Дагестан (2 ед.), Чеченской Республике (2ед.), Республике Татарстан (2ед.). Их размещение сконцентрировано в западной, юго-западной части страны и на Урале.

Минэкономразвития РФ был проведен анализ результативности функционирования ОЭЗ за 2019 [6]. Согласно отчету лидерами признаны ОЭЗ «Липецк», ОЭЗ «Тольятти» и ОЭЗ Татарстана -«Иннополис» и «Алабуга».

Кроме того, в 2015-2019 было сформировано около 100 ТОР (ТОСЭР). Территории опережающего социально-экономического развития представлены, главным образом, в Республике Башкортостан, Республике Татарстан, Приморском крае, Челябинской и Кемеровской областях. Реализация ТОР (ТОСЭР) осуществляется только 54 субъектами РФ. Необходимо отметить, что ТОР (ТОСЭР) в соответствие с действующим законодательством могут быть двух видов: создаваемые на территории Дальневосточного федерального округа (уполномоченным исполнительным органом является Минвостокразвития России) и на территории моногородов (или закрытых административно-территориальных образований - ЗАТО), где уполномоченным ведомством назначено Минэкономразвития РФ. Лиде- рами по количеству ТОСЭР среди субъектов РФ стали Приморский край, а также Республика Татарстан, Республика Башкортостан, в каждом из которых созданы не менее пяти подобных территориальных образований.

Целесообразно выделить несколько субъектов, в которых имеются все виды рассматриваемых инструментов пространственного развития (агломерации, кластеры, ОЭЗ, ТОСЭР): Иркутская область, Алтайский край, Республика Бурятия, Ульяновская область, Саратовская область, Самарская область, Нижегородская область, Республика Татарстан, Республика Башкортостан, Тульская область, Воронежская область. В целом наличие разнообразных форм пространственных структур характеризует развитость региона, позволяя выделить его в качестве основы технологического пространственного каркаса.

Ситуация в макрорегионах РФ обстоит следующим образом (в порядке убывания):

В Центральном макрорегионе размещено 40 пространственных структур, лидеры: г. Москва, Московская область. Наибольшее количество ОЭЗ в РФ - 9 ед., 


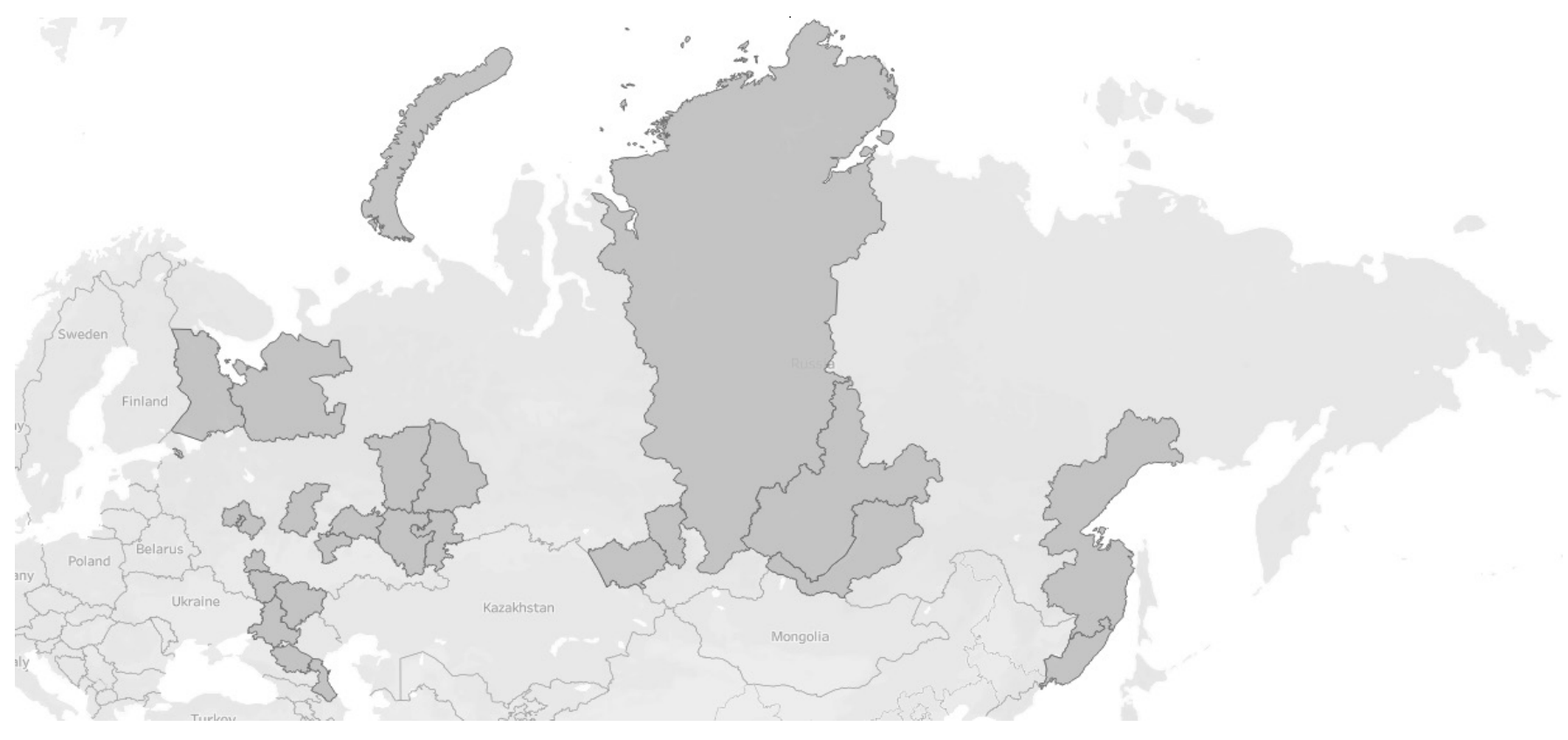

Рис. 2. Потенциальные регионы опорного каркаса пространственного развития России по количеству пространственных структур

Источник: выполнено авторами по результатам исследования

наибольшее количество промышленных кластеров 1 Зед.

В Волго-Камском макрорегионе - 40 структур, лидер - Республика Татарстан. Наибольшее количество потенциальных агломераций в РФ (ед.), и промышленных кластеров (13 ед.), инновационных кластеров - 4ед.

В Волго-Уральском макрорегионе - 32 рассматриваемые структуры, лидер - Республика Башкортостан. Наибольшее количество инновационных кластеров в PB (4шт).

В Дальневосточном макрорегионе - 27 структур, включая свободные порты, в том числе 19 ТОР, 1 ОЭЗ территориального типа (Магаданская обл., территория г. Магадан). Лидером здесь можно считать - Приморский край, где созданы несколько ТОРов и функционирует система свободного порта Владивосток, расположенного на территории 15-ти муниципальных образований этого субъекта России.

В Уральско-Сибирском макрорегионе - 22 структуры, лидер - Челябинская область.

В Южно-Сибирском макрорегионе - 22 структуры, лидер - Алтайский край.

В Северо-Западном макрорегионе - 19 структур, лидер - г. Санкт-Петербург.
В Централь-Черноземном регионе - 16 структур, лидер - Воронежская область.

В Южном макрорегионе - 12 структур, лидер - Ростовская обл.

В Северо-Кавказском макрорегионе - 16 структур, лидер -Республика Дагестан и Ставропольский край.

В Ангаро-Енисейском макрорегионе - 9 структур, лидер - Иркутская обл.

В Северном макрорегионе - 5 структур, лидер Архангельская обл.

Исходя из полученных результатов, можно выделить лидеров в каждом макрорегионе, которые потенциально могу стать основной опорного каркаса пространственной организации страны (таблица 1):

По объективным причинам в целом ряде территориальных образований по состоянию на 01.01.2021 г. отсутствуют сформированные пространственные структуры. В частности, Республика Тыва, Республика Алтай, Ямало-Ненецкий автономный округ, Ханты-Мансийский автономный округ, Республика Северная Осетия - Алания, Республика Калмыкия, Республика Адыгея, Ненецкий автономный округ, Брянская область. Тем не менее, это не означает, что в данных субъектах не осуществляется деятельность по обоснованию создания новых экономических струк- 
тур. Однако для этого необходимы определённые условия, в том числе подготовленные кадры управленцев и проработка специализации каждой ОЭЗ (СЭЗ, ТОР) в отдельности, определение мероприятий, способствующих привлечению резидентов и потенциальных инвесторов [7]. Кроме того, государство должно понимать, в какие сроки можно достичь реальной отдачи на вложенные бюджетные средства. Именно целевые затраты государства являются своеобразным первоначальным взносом в развитие будущих новых экономических территорий.
Подводя итог, отметим, что пространственные структуры играют важную роль в процессе формирования пространственной организации России. Территории с высокой долей размещения инструментов пространственного развития занимают лидирующие позиции в формировании производственного и научно-технологического потенциала, культурного и образовательного уровня будущих поколений. При этом они становятся «локомотивами» экономического роста России.

\section{ЛИТЕРАТУРА}

1. Стратегия пространственного развития РФ до 2025 [Распоряжение Правительства от 13.02.2019 № 207-р (ред. 0т 31.08.2019)] // СПС «Консультант Плюс».— Текст электронный._ URL: http://base.consultant.ru (дата обращения 01.09.2021).

2. Геоиинформационная система Министерство промышленности и торговли РФ: сайт. — URL: https://www.gisip.ru/\#!ru/clusters/ (дата 0бращения 17.08.2021). - Текст электронный.

3. Особые экономические зоны: сайт. — URL: http://www.russez.ru/oez/ (дата обращения 23.09.2021). — Текст электронный.

4. Территории опережающего социально-экономического развития: сайт.— URL: http://invest.tgl.ru/toser/ (дата обращения 16.08.2021).— Текст электронный.

5. Эффект масштаба. Первый рентинг агломераций: отчет PricewatherhouseCoopers. — Текст электронный.— URL: https://www.pwc.ru/ru/assets/ agglomerations-rus-full.pdf (дата обращения 13.09.2021).

6. Отчет о результатах функционирования особых экономических зон за 2019 год и за период с начала функционирования особых экономических зон // Министерство экономического развития.— Текст электронный. — URL: https://www.economy.gov.ru/material/dokumenty/otchet_0_rezultatah_ funkcionirovaniya_osobyh_ekonomicheskih_zon_za_2019_god_i_za_period_s_nachala_funkcionirovaniya_osobyh_ekonomicheskih_zon.html (дата обращения 11.07.2021).

7. Строев, П.В. Современный императив пространственного развития России // Проблемы современной экономики. — 2020.— № 4. (76). — С. 109112.

(с) Шеожев Хасанби Владимирович (KVSheozhev@fa.ru), 